\title{
ANÁLISE DOS ACIDENTES COM MATERIAL BIOLÓGICO OCORRIDOS NO MUNICÍPIO DE UBERABA/MG
}

\section{ANALYSIS OF ACCIDENTS WITH BIOLOGICAL MATERIAL OCCURRED IN THE MUNICIPALITY OF UBERABA/MG}

\author{
Gisele Bento Sgotti \\ Mestranda, Programa de Pós-graduação Saúde Ambiental e Saúde do Trabalhador, UFU \\ gi sgotti@yahoo.com.br \\ Samuel do Carmo Lima \\ Prof. Dr., Programa de Pós-graduação Saúde Ambiental e Saúde do Trabalhador, UFU \\ samuel@ufu.br
}

\begin{abstract}
RESUMO
O objetivo desta pesquisa foi compreender os acidentes de trabalho com material biológico ocorridos no município de Uberaba/MG, notificados no setor de Vigilância Epidemiológica, no período de 2013 a 2017. Trata-se de um estudo retrospectivo descritivo, com abordagem quantitativa. As informações foram obtidas nas fichas de notificação do SINAN (Sistema de Informação de Agravos de Notificação). Os resultados apresentaram 1.160 registros de acidentes de trabalho com materiais biológicos. Observa-se um crescimento expressivo de casos nos anos de 2016 e 2017, com 305 e 415 casos, respectivamente. Em 68,8\% das fichas analisadas, foi aberta a Comunicação de Acidente de Trabalho (CAT); $45,5 \%$ dos trabalhadores eram registrados com carteira assinada, e apenas 3,4\% das empresas eram terceirizadas; $32,8 \%$ dos sujeitos envolvidos tinham ensino médio completo; $40,8 \%$ eram técnicos de enfermagem, $78 \%$ do sexo feminino e $42 \%$ dos envolvidos estavam na faixa etária de 25 a 34 anos. Os acidentes percutâneos tiveram o maior índice de ocorrência, somando $74,6 \%$ dos casos; já $58 \%$ tiveram como agente agulha com lúmen; $52,4 \%$ das fichas indicaram procedimentos com perfurocortantes como circunstâncias do acidente; o sangue foi o material orgânico encontrado em $79,1 \%$ dos registros; em $75,8 \%$ dos casos, o profissional fazia uso de luvas e, em $42 \%$ de avental. Entende-se que tal problematização engloba questões complexas e sua resolutividade esta pautada na interação entre legisladores, empregadores e trabalhadores.
\end{abstract}

Palavras chave: Acidentes ocupacionais. Riscos biológicos. Equipe de enfermagem.

\begin{abstract}
This research analyzed occupational accidents with biological materials that took place in the city of Uberaba, state of Minas Gerais, Brazil. The events analyzed were reported by the Epidemiological Surveillance sector between 2013 and 2017. This is a retrospective descriptive study with a quantitative approach. The data was collected from records of the Brazilian Information System for Notifiable Diseases (SINAN). The total of 1,160 accidents with biological materials were reported over the period analyzed. We found a significant increase in the number of events in 2016 and 2017, with 305 and 415 events, respectively; the Work Accident Report (CAT) was filled in $68.8 \%$ of the records analyzed; $45.5 \%$ of workers had a formal contract, and only $3.4 \%$ of the companies were outsourcing providers; $32.8 \%$ of workers involved in accidents had complete high school; $40.8 \%$ were nursing technicians; $78 \%$ were women; and $42 \%$ were between 25 and 34 years old. Percutaneous accidents were the most common, responsible for $74.6 \%$ of the events; lumen needle was present in $58 \% ; 52.4 \%$ of the reports indicated procedures with piercing-cutting equipment; blood was the organic material found in $79.1 \%$ of the records; workers were wearing gloves in $75.8 \%$ of the accidents and an apron in $42 \%$. These research results contribute to the comprehension of such accidents, helping to define practices to solve this problem.
\end{abstract}

Keywords: Occupational accidents. Biological hazards. Nursing staff.

Recebido em: 24/09/2019

Aceito para publicação em: 04/03/2020 


\section{INTRODUÇÃO}

Inúmeros são os fatores que influenciam o bem-estar social, físico e psíquico do homem. $\mathrm{O}$ trabalho não fica de fora desse contexto, atuando de maneira categórica em suas atividades cotidianas. Quando o trabalho é capaz de suprir as necessidades de subsistência, considera-se seu desempenho como positivo. Em contrapartida, é caracterizado como negativo quando coloca o trabalhador exposto a riscos ocupacionais, podendo ocasionar danos diretos ou indiretos à saúde do indivíduo (SANTOS JUNIOR et al., 2015).

Os riscos ocupacionais dentro do ambiente de trabalho podem ser classificados como reais, ocultos ou latentes. Os denominados ocultos referem-se aos riscos dos quais o profissional não tem ciência da existência, seja por desconhecimento ou ingenuidade. São várias as razões que contribuem para que os riscos tornem-se ocultos, das quais destacamos a irresponsabilidade e a negligência perante a saúde do trabalhador. Já o risco latente evidencia-se perante uma circunstância emergencial ou sob condições de estresse, em que o trabalhador pode até ter conhecimento do risco a que está exposto, mas a situação força-o a expor-se de maneira acentuada. Os riscos reais são aqueles conhecidos, mas que não oferecem possibilidade de controle (BAUMGART et al., 2017).

No que se refere à saúde do trabalhador, existe uma variedade de riscos inerentes às suas atividades laborais desempenhadas. Quanto aos profissionais da área da saúde, o risco biológico possui importante significância. Está associado à possibilidade de contato com sangue ou fluidos orgânicos, potencialmente capazes de transmitir agentes patogênicos causadores de doenças. As formas de exposição, incluem a inoculação percutânea, por intermédio de agulhas ou objetos cortantes e o contato direto com pele e mucosas (Al-KHATIB et al., 2015).

Os riscos relacionados ao ambiente de trabalho, caso não sejam controlados podem ocasionar acidentes de trabalho. $\mathrm{O}$ acidente de trabalho é definido como aquele ocorrido durante o exercício do trabalho, provocando lesão corporal ou perturbação funcional que acarrete morte, perda ou redução, permanente ou temporária, da capacidade de trabalho (BRASIL, 1976). Esse tipo de acidente sempre esteve presente no desenvolvimento das atividades laborais praticadas pelo ser humano; contudo, apenas a partir do século XX, com o intenso avanço tecnológico e industrial, é que ele passou a ter maior evidência. Já os acidentes de trabalho envolvendo exposição a material biológico só tiveram papel importante com a adoção de medidas preventivas no início da década de 1980 . Apesar de eles já serem conhecidos há mais tempo, cerca de 40 anos antes, somente com a epidemia de infecção pelo vírus da imunodeficiência humana (HIV) é que protocolos de atendimento foram implementados, assim como a preconização de medidas profiláticas frente à exposição ocupacional a contaminantes biológicos (BRASIL, 2004).

A Norma Regulamentadora (NR) 32 estabelece diretrizes básicas para a elaboração de medidas de segurança e proteção à saúde dos trabalhadores dos serviços de saúde e daqueles que exercem atividades de promoção à assistência à saúde em geral. Ela classifica os riscos aos quais os trabalhadores da área da saúde estão submetidos em físicos, químicos e biológicos, porém o risco biológico possui especial relevância (BRASIL, 2005).

A NR 32 também é responsável pela implementação de condutas referentes à saúde e à segurança dos profissionais da área da saúde, regulamentando medidas preventivas e a utilização de equipamentos de proteção individual (EPI) e coletiva (EPC). Contudo, para o controle da ocorrência de acidentes ocupacionais com material biológico, que envolvem múltiplos riscos, a adoção de condutas efetivas de conscientização do trabalhador são imprescindíveis para a diminuição desses acidentes (AI-KHATIB et al., 2015).

Sempre que um acidente de trabalho acontece, a Comunicação de Acidentes de Trabalho (CAT) deve ser preenchida sempre e, posteriormente, encaminhada ao Instituto Nacional de Previdência Social (INSS), tornando-se uma importante fonte de informação para a pesquisa e a vigilância epidemiológica (BRASIL,1999).

Do mesmo modo, o Ministério da Saúde exige a notificação compulsória no Sinan de vários agravos à saúde, dentre eles o acidente de trabalho com material biológico. Várias portarias ressaltam a importância da notificação desse agravo, com destaque para a Portaria $n^{\circ} 104 / 2011$, que reitera a necessidade de notificação de 11 agravos relacionados à saúde do trabalhador, bem como a exigência, por parte dos setores de vigilância em saúde estaduais e municipais, de fazer essa notificação (BRASIL, 2011).

Neste contexto, a notificação compulsória representa uma das mais importantes ferramentas para a 
compreensão dos acidentes e doenças associados ao trabalho. Ela possibilita conhecer detalhadamente os agentes causadores de danos à saúde dos trabalhadores.

Com base na análise das informações contidas na ficha de notificação do Sinan, estratégias de prevenção e controle de agravos podem ser traçadas visando a manutenção da saúde do trabalhador. Desse modo, a vigilância epidemiológica deve monitorar os acidentes de trabalho por meio de uma investigação diagnóstica, para posterior definição e planejamento de metas de redução dos acidentes. Uma vez compreendendo o perfil epidemiológico dos acidentes de trabalho, é possível estabelecer intervenções no processo laboral para tornar mais efetivas as ações de prevenção (BARBOSA et al., 2017).

Tendo em vista o que foi apresentado, este trabalho teve como objetivo compreender os acidentes de trabalho com material biológico ocorridos no município de Uberaba/MG, notificados no setor de Vigilância Epidemiológica na referida cidade, no período de 2013 a 2017, assim como analisar, interpretar e comparar os dados coletados.

\section{METODOLOGIA}

O presente trabalho foi realizado por meio de uma pesquisa documental, na qual foram utilizados dados primários coletados em fichas de notificação do Sinan referentes aos acidentes de trabalho com material biológico, apresentados ao setor de Vigilância Epidemiológica da Secretaria Municipal de Saúde do município de Uberaba/MG, notificados no período entre 2013 e 2017. O período de coleta de dados se deu entre julho de 2018 e agosto de 2018. O município de Uberaba está localizado no estado de Minas Gerais, na região do Triângulo Mineiro, e tem uma população estimada de 330.361 habitantes (IBGE, 2018).

Trata-se de um estudo retrospectivo descritivo, com abordagem quantitativa. A princípio, realizou-se o levantamento das fichas de notificação e, em seguida, a análise dos dados de acordo com o perfil dos trabalhadores que sofreram o acidente e as caraterísticas do evento em questão. Foram avaliadas as seguintes informações das fichas de notificação: agente, circunstância do acidente, escolaridade, faixa etária, ocupação, material orgânico, situação no mercado de trabalho, tipo de exposição e uso de EPI. Os dados obtidos foram lançados em uma planilha eletrônica Microsoft Excel 15.0 (versão de 2013), na qual foi possível construir tabelas e gráficos e assim discutir e analisar os referidos dados em questão.

Todos os acidentes de trabalho com material biológico notificados no Sinan no período de 2013 a 2017 foram incluídos no trabalho; foram excluídos da pesquisa os acidentes não notificados no Sinan no município de Uberaba/MG neste mesmo período.

Em cumprimento com a resolução 466/2012, do Conselho Nacional de Saúde, a pesquisa foi submetida à apreciação de Comitê de Ética em Pesquisa e aprovada com os pareceres de $\mathrm{n}$. 2.762.336 (UFU), e n. 2.997 .603 (UFU).

\section{RESULTADOS E DISCUSSÃO}

No período de 2013 a 2017, foram notificados, no município de Uberaba/MG, um total de 1.160 casos de acidentes de trabalho com material biológico. Nesse período, a CAT foi emitida somente em $68,8 \%$ das notificações de acidentes com material biológico no Sinan. Como supracitado, a CAT possui importante papel nos direitos do trabalhador; porém, ainda é significativo o número de eventos que não são comunicados à Previdência Social, o que não só prejudica o trabalhador acidentado, mas também impede o conhecimento da real situação das condições de trabalho em nosso país.

O Gráfico 1 aponta o crescimento no número de notificações entre os anos de 2013 e 2017. Observase que, nos anos de 2013 e 2014, ocorreram os menores índices de agravos, indicando 120 e 124 casos, respectivamente. Já em 2015, foram registrados 196 eventos, representando um acréscimo de $16,9 \%$ em relação ao ano anterior. Nos dois anos subsequentes, houve um aumento ainda maior nos registros do Sinan, com 305 notificações em 2016 e 415 em 2017. 
Gráfico 1 - Uberaba/MG: número de notificações no Sinan entre os anos de 2013 e 2017

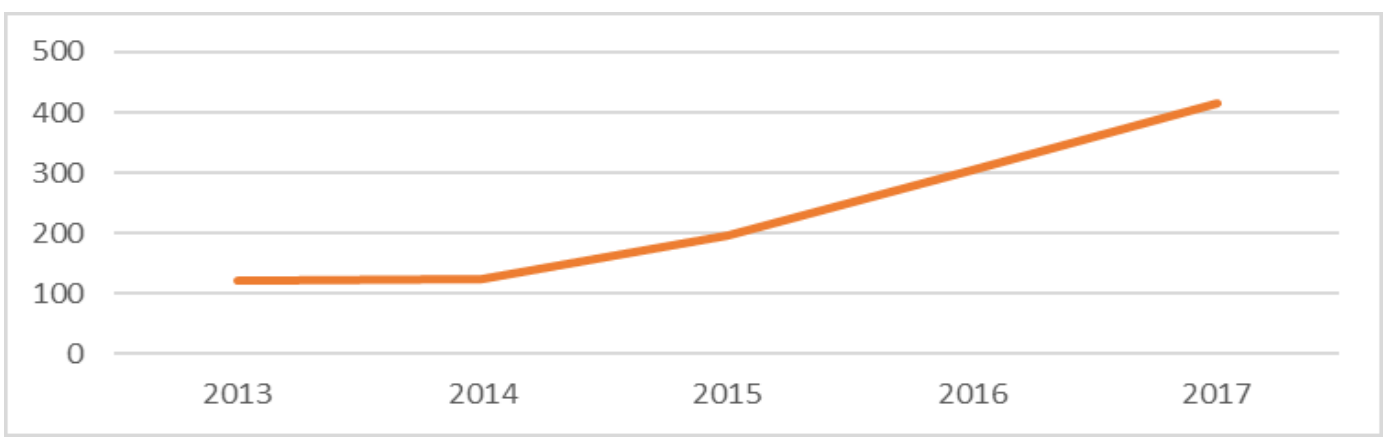

Fonte: Elaboração dos autores (2019).

Presume-se que esse aumento nas notificações ocorreu devido a uma maior fiscalização quanto à obrigatoriedade dos registros de acidentes de trabalho com material biológico. Além disso, acreditase que trabalhadores e empregadores estão sendo conscientizados de que o registro dos acidentes de trabalho é um direito do trabalhador e importante para o sistema de vigilância de acidentes e agravos. Desse modo, o crescimento do número de casos notificados não deve ser atribuído somente ao aumento do número de acidentes. Porém, mesmo diante desse aumento nas notificações e do fato de ela ser compulsória, estima-se que apenas 5\% dos acidentes de trabalho com material biológico são notificados no Brasil, o que confirma a subnotificação elevada (SANTOS JUNIOR et al., 2015).

A Tabela 1 mostra a situação empregatícia no mercado de trabalho dos indivíduos que sofreram acidentes de trabalho com material biológico. A maioria encontra-se empregada com carteira assinada (45,5\%). Os servidores públicos estatutários e celetistas juntos somam $25,4 \%$.

Tabela 1 - Uberaba/MG: situação no mercado de trabalho dos indivíduos que sofreram acidentes de trabalho com material biológico notificados no Sinan entre 2013 e 2017

\begin{tabular}{lcc}
\hline Situação no mercado trabalho & Quantidade & $(\%)$ \\
\hline Desempregado & 2 & 0,2 \\
Cooperativado & 2 & 0,2 \\
Trabalhador avulso & 3 & 0,3 \\
Trabalho temporário & 8 & 0,7 \\
Autônomo/conta própria & 11 & 0,9 \\
Empregado não registrado & 15 & 1,3 \\
Não informado & 59 & 5,1 \\
Ignorado & 61 & 5,3 \\
Servidor público estatutário & 106 & 9,1 \\
Outros & 176 & 15,2 \\
Servidor público celetista & 189 & 16,3 \\
Empregado registrado com carteira assinada & 528 & 45,5 \\
\hline TOTAL & 1.160 & 100 \\
\hline
\end{tabular}

Fonte: Elaboração dos autores (2019).

Outra característica observada foi que, das empresas que notificaram, apenas $3,4 \%$ são terceirizadas, e $76,1 \%$ são de empregadores diretos. Esse índice mostra que os trabalhadores vítimas desses agravos estão empregados em instituições cuja mão de obra está relacionada à atividade-fim do estabelecimento.

A presente pesquisa utilizou os registros feitos entre os anos de 2013 e 2017 , e somente em 2017 a lei da terceirização foi aprovada, permitindo a terceirização de todas as atividades oferecidas por uma empresa, inclusive a atividade-fim (BRASIL, 2017).

Vale ressaltar que a notificação no Sinan referente aos ATMB não está vinculada diretamente a ocupação do indivíduo no mercado de trabalho, por este motivo os desempregados aparecem na tabela 1. Quanto ao número elevado de não informados e ignorados está relacionado ao não 
preenchimento adequado das fichas em questão.

O Gráfico 2 demonstra que, dentre os profissionais que sofreram acidentes com material biológico, 381 tinham ensino médio completo (32\%), 183 tinham ensino superior incompleto $(15,8 \%)$ e 310 tinham ensino superior completo (26,7\%). Em 234 notificações $(20,2 \%)$, a informação de escolaridade dos acidentados não pode ser obtida, constando como ignorada, não se aplica ou não informada.

Gráfico 2 - Uberaba/MG: escolaridade dos indivíduos que sofreram acidentes de trabalho com material biológico notificados no Sinan entre 2013 e 2017

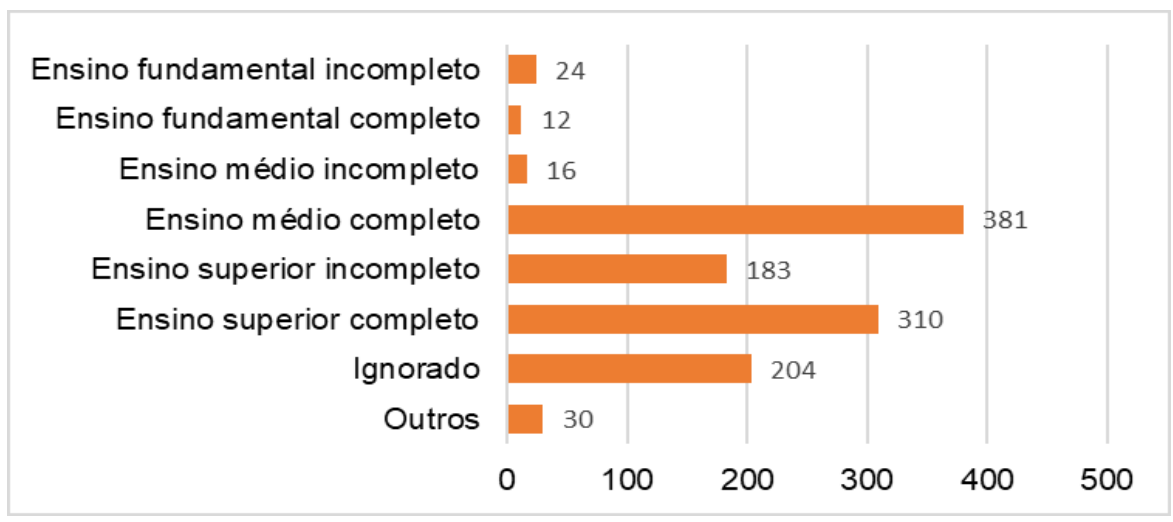

Fonte: Elaboração dos autores (2019).

Associado ao Gráfico 2, o quesito Ocupação (Gráfico 3) apontou que 40,8\% das pessoas que sofreram acidente de trabalho com material biológico são técnicos de enfermagem; $2,3 \%$ são auxiliares de enfermagem; 10,9\% são enfermeiros; $14,91 \%$ são estudantes, não sendo informado o nível de ensino destes indivíduos; $10 \%$ são médicos; $1,55 \%$ são dentistas; $13,51 \%$ são outros profissionais na área da saúde ou em outras áreas de atuação que não estão discriminadas na ficha do Sinan. Observa-se que a maioria dos profissionais pertence à equipe de enfermagem, totalizando $54 \%$ dos indivíduos que sofreram agravo.

Gráfico 3 - Uberaba/MG: ocupação dos indivíduos que sofreram acidentes de trabalho com material biológico notificados no Sinan entre 2013 e 2017

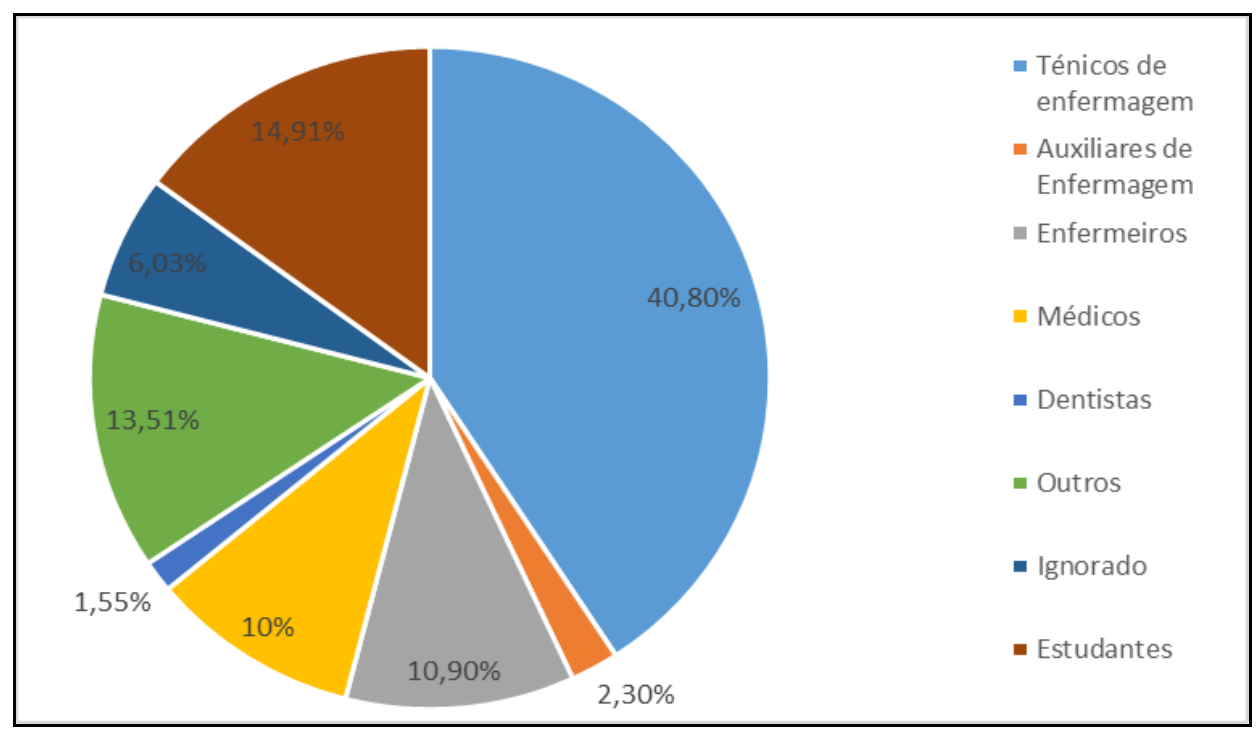

Fonte: Elaboração dos autores (2019). 
Miranda et al. (2017) traçaram o perfil dos trabalhadores brasileiros que sofreram acidentes com material biológico, mostrando que o maior número de acidentes ocorreu entre os trabalhadores da enfermagem, totalizando $47,3 \%$ dos casos. Essa mesma pesquisa demonstra que a maioria dos acidentes ocorreu com profissionais com ensino médio completo e superior incompleto. A categoria Estudante apresentou percentual significativo dentre os acidentados, $14,9 \%$ dos casos.

O município de Uberaba tem duas importantes universidades que oferecem cursos na área da saúde, fator relevante para justificar a quantidade de estudantes que realizam estágios práticos capazes de expor esses indivíduos ao risco de acidentes com material biológico. Os discentes se enquadram em uma categoria considerada com pouca experiência e pouca de habilidade técnica na execução das tarefas, o que pode ocasionar aumento no risco de se acidentarem com material biológico (MIRANDA et al., 2017).

A maior parte dos trabalhadores que sofreram acidente com material biológico foram do sexo feminino $(78 \%)$. Os indivíduos do sexo masculino representaram $22 \%$ do total de eventos. Tendo em vista que a presente pesquisa apontou que mais de $50 \%$ dos indivíduos que sofreram acidente com material biológico pertencem à equipe de enfermagem, salientamos que a área da enfermagem é histórica e estruturalmente feminina. Machado et al. (2016) mostraram que os profissionais com registro ativo no Conselho Federal de Enfermagem somam um total de um 1,8 milhão de pessoas. Destes, $85,1 \%$ são do sexo feminino. Isso explica por que mais de $50 \%$ dos indivíduos que sofreram acidentes com material biológico na equipe de enfermagem são do sexo feminino.

Com relação à idade, o Gráfico 4 mostra que $42 \%$ dos profissionais estão na faixa etária dos 25 aos 34 anos. Os indivíduos com idade entre 18 e 24 anos e entre 35 e 44 anos correspondem, respectivamente, a $21,4 \%$ e $22 \%$. Desse modo, verifica-se uma predominância jovem nesse grupo de trabalhadores que sofreram acidentes com material biológico, pois mais de $50 \%$ têm idade inferior a 34 anos. Novamente, pode-se fazer um paralelo com o que já foi mencionado sobre a maioria dos profissionais estarem enquadrados na área da enfermagem. De acordo com Machado et al. (2016), cerca de $40 \%$ desses profissionais com registro ativo têm até 35 anos. Também destacamos a quantidade de estudantes que sofreram esse tipo de agravo, que é formada de população predominantemente jovem. O numero elevado de ATMB entre os trabalhadores jovens também pode relacionar-se a falta de experiência e a falta de prática no desempenho de suas atividades, necessitando de maior tempo para ambientação e aquisição de práticas relativas à sua atuação (MIRANDA et al., 2017).

Gráfico 4 - Uberaba/MG: faixa etária dos indivíduos que sofreram acidentes de trabalho com material biológico notificados no Sinan entre 2013 e 2017

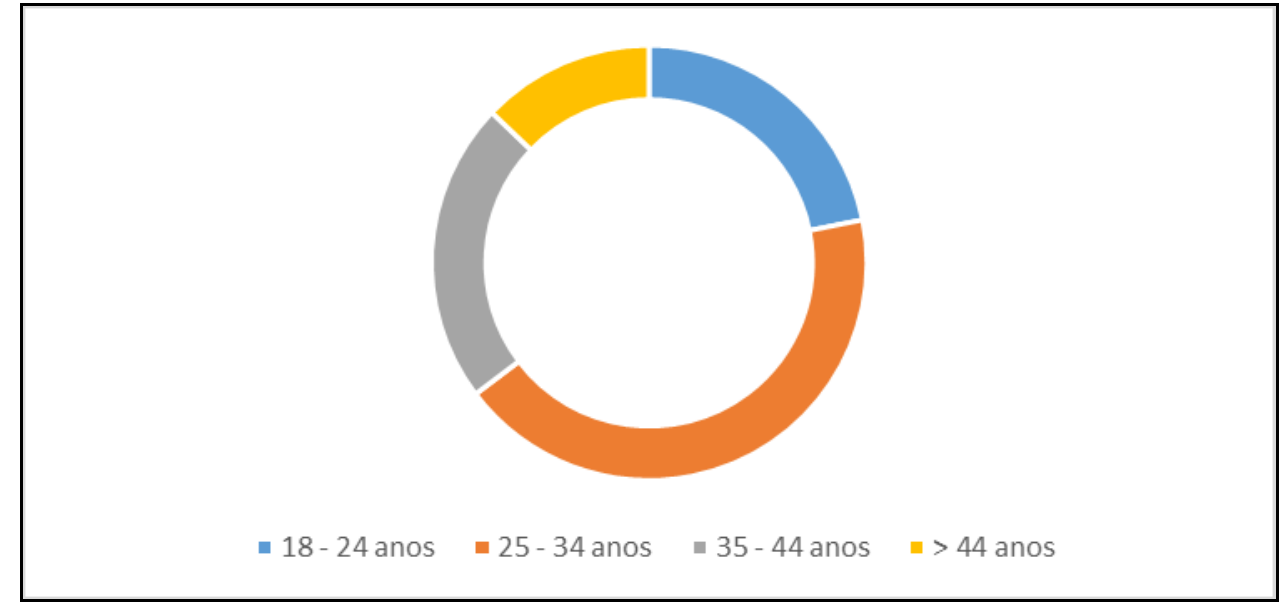

Fonte: Elaboração dos autores (2019).

A Tabela 2 apresenta o agente responsável pelo acidente com material biológico. Um total de 673 (58\%) sujeitos acidentaram-se com agulha com lúmen e 79 (6.8\%) com agulha sem lúmen. Acidentes com agulhas representam o maior índice de transmissão de doenças infecciosas, principalmente as com lúmen, pois podem armazenar em seu interior fluidos contagiosos. Em 2008, o CDC (Center for 
Disease Control and Prevention) calculou que ocorriam cerca de 385 mil acidentes com perfurocortantes por ano em todo o mundo. O quesito 'Outros' teve representatividade expressiva; porém, as fichas de notificação não especificaram quais agentes compunham esse campo, englobando os mais diversos agentes capazes de ocasionar acidentes contendo material biológico.

Tabela 2 - Uberaba/MG: agentes responsáveis pelos acidentes de trabalho com material biológico notificados no Sinan entre 2013 e 2017

\begin{tabular}{lcc}
\hline AGENTE & Quantidade & $(\%)$ \\
\hline Vidros & 3 & 0.2 \\
Não informado & 5 & 0.4 \\
Intracath & 23 & 2.0 \\
Lâmina/lanceta (qualquer tipo) & 46 & 4.0 \\
Ignorado & 60 & 5.2 \\
Agulha sem lúmen/maciça & 79 & 6.8 \\
Outros & 271 & 23.4 \\
Agulha com lúmen (luz) & 673 & 58.0 \\
\hline Total & 1.160 & 100 \\
\hline
\end{tabular}

Fonte: Elaboração dos autores (2019).

Condutas vêm sendo tomadas em diversos países com o objetivo de diminuir os acidentes com perfurocortantes. Dispositivos de segurança são uma estratégia utilizada em diversos países para minimizar danos oriundo da manipulação de perfurocortantes. No Japão uma pesquisa foi realizaad visando identificar a eficácia destes equipamentos. Foi identificado que sua utilização reduz substancialmente a incidencia de acidentes de trabalho envolvendo perfurocortantes (FUKUDA; YAMANAKA, 2016).

A Tabela 3 fornece informações quanto à integridade da pele dos acidentados; porém, em $51,5 \%$ dos registros, esse dado não foi informado. Em $40,1 \%$ das fichas, foi assinalada a opção Pele íntegra, e, em 4,9\%, Pele não íntegra, ou seja, se, no momento do acidente, sua pele estava íntegra ou não. Já quanto aos tipos de exposição, a Percutânea e a Mucosa (oral/ocular) representaram, respectivamente, $74,6 \%$ e $17,6 \%$ do total de eventos. Em estudo realizado na Grande Florianópolis, em $73 \%$ dos casos houve exposição percutânea, e, em 10\%, de mucosas. Neste caso, Pele íntegra e Não íntegra constaram em, respectivamente, $10 \%$ e $7 \%$ dos acidentes (SANTOS JUNIOR et al., 2015).

O risco de um indivíduo ser contaminado em um acidente com material biológico depende de vários fatores, como extensão da lesão, quantidade de material biológico envolvido, condição de saúde da fonte e do acidentado, o tipo de exposição etc. Nesse sentido, a pele íntegra constitui barreira importante na proteção contra possíveis contaminações, enquanto a exposição percutânea ou da mucosa apresenta maior risco de aquisição de alguma doença infectocontagiosa (SANTOS JUNIOR et al., 2015).

Tabela 3 - Uberaba/MG: tipo de exposição dos acidentes de trabalho com material biológico notificados no Sinan entre 2013 e 2017

\begin{tabular}{lcc|lcc}
\hline INTEGRIDADE DA PELE & Quant. & $(\%)$ & TIPO DE EXPOSIÇÃO & Quant. & $(\%)$ \\
\hline Pele íntegra & 465 & 40.1 & Percutânea & 865 & 74.6 \\
Pele não íntegra & 57 & 4.9 & Mucosa (oral/ocular) & 204 & 17.6 \\
Ignorado & 41 & 3.5 & Ignorado & 9 & 0.8 \\
Não informado & 597 & 51.5 & Não informado & 82 & 7.1 \\
\hline TOTAL & 1.160 & 100,00 & TOTAL & 1.160 & 100,00 \\
\hline
\end{tabular}

Fonte: Elaboração dos autores (2019).

Sabe-se que os fluidos com potencial de transmitir doenças compreendem o sangue, urina, liquor, secreções do trato respiratório e digestivo, liquido aminiótico, dentre outros. A Tabela 4 demonstra que, em $79,1 \%$ dos casos, o material biológico envolvido nos acidentes foi o sangue. No estudo já refeido, realizado na Grande Florianópolis, em $69,49 \%$ dos acidentes, o sangue foi o fluido envolvido 
(BARROS et al., 2016). Outra pesquisa, realizada em um hospital público de referência em doenças infecciosas no estado de Minas Gerais, mostrou que, em 58,1\% dos casos, o material orgânico também foi o sangue (CARVALHO et al., 2016).

Tabela 4 - Uberaba/MG: material orgânico envolvido nos acidentes de trabalho com material biológico notificados no Sinan entre 2013 e 2017

\begin{tabular}{lcc}
\hline \multicolumn{1}{c}{ MATERIAL ORGÂNICO } & Quantidade & $(\%)$ \\
\hline Líquido amniótico & 1 & 0.1 \\
Soro/plasma & 2 & 0.2 \\
Líquido pleural & 3 & 0.3 \\
Líquido ascítico & 3 & 0.3 \\
Líquor & 7 & 0.6 \\
Não informado & 9 & 0.8 \\
\hline Ignorado & 41 & 3.5 \\
Fluido com sangue & 67 & 5.8 \\
Outros & 109 & 9.4 \\
Sangue TOTAL & 918 & 79.1 \\
& 1.160 & 100 \\
\hline
\end{tabular}

Fonte: Elaboração dos autores (2019).

Machado et al. (2017), em um trabalho realizado em um hospital de referência de doenças infectocontagiosas do estado de Goiás, mostrou que $49,8 \%$ dos acidentes com material biológico continham sangue ou fluido com sangue. Conhecer o fluido envolvido no acidente com material biológico é fundamental para definir as condutas pós-exposição. Os que envolvem sangue devem ser tratados como casos de emergência. Exames da fonte e do acidentado precisam ser coletados, e, caso o paciente fonte não seja conhecido, profilaxias referentes à infecção do HIV e da hepatite B devem ser iniciadas imediatamente (BARROS et al., 2016).

A Tabela 5 apresenta a circunstância do acidente. Nela, vemos que o item Procedimento cirúrgico representou $13,4 \%$ dos casos, ficando atrás somente do item 'Outros', que teve 20,3\%. Também exibe número expressivo a Administração de medicação endovenosa, com $8,8 \%$, e o Procedimento laboratorial, com $8,3 \%$. É interessante observar que a maior parte das circunstâncias, cerca de $52,4 \%$, envolve objetos perfurocortantes. Santos Junior et al. (2014) afirmam que os perfurocortantes são os instrumentos que mais ocasionam acidentes de trabalho com material biológico. Outra pesquisa sobre acidentes com material biológico na equipe de enfermagem demonstrou que $89,5 \%$ dos eventos acontecem durante o manuseio de perfurocortantes (BARROS et al., 2016).

Tabela 5 - Uberaba/MG: circunstâncias dos acidentes de trabalho com material biológico notificados no Sinan entre 2013 e 2017

\begin{tabular}{lcc}
\hline CIRCUNSTÂNCIA DO ACIDENTE & Quantidade & $(\%)$ \\
\hline Lavanderia & 5 & 0.4 \\
Não informado & 6 & 0.5 \\
Ignorado & 25 & 2.2 \\
Lavagem de material & 26 & 2.2 \\
Procedimento laboratorial & 33 & 2.8 \\
Reencape & 33 & 2.8 \\
Manipulação de caixa com material perfurocortante & 43 & 3.7 \\
Procedimento odontológico & 65 & 5.6 \\
Dextro & 96 & 8.3 \\
Punção venosa/arterial & 114 & 9,8 \\
Descarte inadequado de material perfurocortante & 115 & 9,9 \\
Procedimento cirúrgico & 155 & 13.4 \\
Administração de medicação & 208 & 17,9 \\
Outros & 236 & 20.3 \\
\hline TOTAL & 1.160 & 100 \\
\hline
\end{tabular}

Fonte: Elaboração dos autores (2019). 
Conforme as circunstâncias dos acidentes, a maioria deles poderia ter sido evitada com medidas preventivas, como a adoção de precauções-padrão. Por isso, a NR 32 estabelece diretrizes básicas para implementação de medidas de proteção à segurança e à saúde dos trabalhadores em serviços de saúde e determina que a capacitação dos profissionais aconteça no início das atividades, ou seja, na admissão do colaborador, e de forma continuada, ministrada por profissionais capacitados (MACHI JUNIOR et al., 2014).

Tais precauções representam um conjunto de medidas que devem ser tomadas durante todo o tempo e que precisam estar presentes em todos os cuidados prestados aos pacientes, visando minimizar o risco de aquisição e a transmissão de infecções. Elas incluem higienização das mãos, desinfecção de superfícies e equipamentos e utilização de EPI e EPC (PHILLIPS et al., 2012). A Tabela 6 complementa os dados anteriores, pois mostra como a utilização de EPI foi adotada nos casos estudados nesta pesquisa.

Tabela 6 - Uberaba/MG: uso de equipamentos de proteção individual pelos indivíduos que sofreram acidentes de trabalho com material biológico notificados no Sinan entre 2013 e 2017

\begin{tabular}{lll} 
USO DE EPI (aceita mais de uma opção) & Quantidade & \multicolumn{1}{c}{$(\%)$} \\
\hline Proteção facial & 81 & 6,98 \\
Óculos & 179 & 15,43 \\
Bota & 232 & 20,0 \\
Máscara & 270 & 23,27 \\
Avental & 489 & 42,1 \\
Luva & 871 & 75,8 \\
\hline
\end{tabular}

Fonte: Elaboração dos autores (2019).

A luva foi o EPI mais usado, durante os acidentes, estando presente em $75,8 \%$ dos eventos. Em segundo lugar, ficou o avental, em $42,1 \%$ dos casos, seguido da bota, em $20 \%$ dos registros. Em $15,43 \%$ dos casos, os óculos foram utilizados, e, em $23,27 \%$, a máscara. A proteção facial foi empregada em $6,98 \%$ dos eventos estudados. Estes dados são semelhantes a outros estudos realizados no Brasil.

Um estudo realizado em um hospital de grande porte da Amazônia Legal mostrou que a utilização de luvas ocorreu em $81,73 \%$ dos casos estudados; avental, em 59,62\%; óculos, em 23,08\%; máscara, em $43,27 \%$; e protetor facial e botas, em apenas $4,41 \%$ (SOARES et al., 2018). Um outro trabalho realizado em um município do noroeste do estado de São Paulo mostrou que, em 96,6\% dos casos notificados, os indivíduos faziam uso de luvas; avental, em 88,2\%; máscara, em 10,7\%; e óculos, em $10,7 \%$.

Um estudo sobre a percepção dos profissionais quanto aos acidentes de trabalho revelou que eles reconheciam os EPIs e os tinham disponíveis no trabalho, mas não os utilizavam em todas as atividades (AYDIN et al., 2018).

Tendo em vista tais resultados, que os EPIs ainda não são utilizados por grande número de profissionais como são equipamentos indispensável durante a realização de procedimentos e atividades com risco de contaminação com material biológico, medidas de prevenção, com educação e promoção da saúde precisam ser intensificadas. Dessa forma, a conscientização dos profissionais para a utilização dos EPIs torna-se a principal estratégia de prevenção de acidentes, visando melhores condições de trabalho e segurança durante o desempenho de suas atividades laborais (AlKHATIBet al., 2015).

\section{CONSIDERAÇÕES FINAIS}

Os acidentes de trabalho com material biológico têm impacto importante no campo da saúde do trabalhador. A presente pesquisa demonstra que, apesar das inovações referentes à prevenção desses agravos, os índices ainda são altos. Muitos esforços estão sendo direcionados para a prevenção dos ATMB, mas seu sucesso depende não somente da normatização e da obrigatoriedade dos registros; é necessário que haja uma maior sinergia de esforços entre legisladores, 
empregadores e trabalhadores, atentos com o mesmo objetivo, de reduzir a ocorrência desses agravos.

Os legisladores, frente a prevenção dos ATMB, devem elaborar normas e leis devem ser acessíveis e transformadoras, capazes de serem observadas, tanto pelos empregadores quanto pelos trabalhadores, de maneira efetiva. Mas, a complexidade do problema exige mais do que a simples normatização das práticas e procedimentos, porque somente os regulamentos pré-definidos não são capazes de alterar o comportamento dos indivíduos.

Os empregadores possuem a obrigação de oferecer subsídios para a segurança de seus colaboradores. Além disso, é de sua respondabilidade a oferta de EPI adequados e a capacitação, visando a prevenção dos ATMB. No entanto, gestores e empregados precisam estar em sintonia, para que a enigmática conjuntura destes agravos sejam desvendados e solucionados, para que haja efetiva prevenção dos acidentes.

Quanto aos trabalhadores, estes possuem a incumbência de apreender todo o conhecimento disponibilizado durante as capacitações, bem como colocá-lo em prática. É necessário comprometimento dos colaboradores quanto à prevenção destes agravos, compartilhando com os demais envolvidos a responsabilidade de zelar pela sua própria saúde. O enganjamento dos profissionais que estão sob o risco de sofrer ATMB representa um dos principais pilares de sustentação na diminuição dos índices destes agravos.

Espera-se que os resultados desta pesquisa possam contribuir para aumentar a compreensão sobre os acidentes de trabalho com material biológico, contribuindo para uma maior consciência do problema em questão, para o estabelecimento de condutas que ajudem a preservar a saúde e a vida dos trabalhadores.

\section{AGRADECIMENTOS}

À Secretaria Municipal de Saúde do município de Uberaba/MG, por disponibilizar os dados registrados no Sinan e no setor de Vigilância Epidemiológica, em especial à enfermeira Luciana Silva Bessa.

\section{REFERÊNCIAS}

Al-KHATIB, I. A. et al. Occupational safety precautions among nurses at four hospitals, Nablus District, Palestine. The International Journal of Occupational and Environmental Medicine, Shiraz, v. 6, n. 4, p. 243-246, oct. 2015. DOI: 10.15171/ijoem.2015.581. Available en: <http://www.theijoem.com/ijoem/index.php/ijoem/article/view/581>. Access: 12 sept. 2017. https://doi.org/10.15171/ijoem.2015.581

AYDIN, N. N. et al. An Assessment of Sharps Injuries in Healthcare Workers. Viral Hepatitis Journal, Trebizonda, v. 24, n. 3, p. 75-78, 2018. DOI: 10.4274/vhd.2018.0015. Available en: <file:///E:/Documentos/Downloads/10.4274vhd.2018.0015.pdf.>. $\quad$ Access: 14 set. 2019. https://doi.org/10.4274/vhd.2018.0015

BARBOSA, A. S. A. et al. Subnotificação de acidente ocupacional com materiais biológicos entre profissionais de Enfermagem em um hospital público. Revista Brasileira de Medicina do Trabalho, São Paulo, v. 15, n. 1, p. 12-17, 2017. DOI: 10.5327/Z1679443520177034. Disponível em: <file:///E:/Documentos/Downloads/v15n1a03\%20(4).pdf>. Acesso em: 22 de out. 2019. https://doi.org/10.5327/Z1679443520177034

BARROS, D. X. et al. Análise de 10 anos de acidentes com material biológico entre a equipe de enfermagem. Revista Eletrônica de Enfermagem, Goiânia, v. 18, 2016. DOI: http://dx.doi.org/10.5216/ree.v18.35493. <https://revistas.ufg.br/fen/article/view/35493>. Acesso em: 23 abr. 2019 . https://doi.org/10.5216/ree.v18.35493

BAUMGART, B. Z. et al. Riscos ocupacionais e equipamentos de proteção individual em bombeiros da Brigada Militar. Ciência \& Saúde, Porto Alegre, v. 10, n. 1, p. 28-33. 2017. DOI: http://dx.doi.org/10.15448/1983-652X.2017.1.00000. Disponível em: $<$ http://revistaseletronicas.pucrs.br/ojs/index.php/faenfi/article/view/24399/15407>. Acesso em: 17 de 


\section{nov. 2019. https://doi.org/10.15448/1983-652X.2017.1.24399}

BRASIL. Lei $n^{\circ} 6.367$, de 19 de outubro de 1976. Dispõe sobre o seguro de acidentes do trabalho a cargo do INPS e dá outras providências. Diário Oficial da União, Brasília, DF, 21 out. 1976. Disponível em: http://www.planalto.gov.br/ccivil_03/LEIS/L6367.htm. Acesso em: 23 abr. 2019.

BRASIL. Decreto n 3048, de 6 de maio de 1999. Aprova o Regulamento da Previdência Social, e dá outras providências. Diário Oficial da União, Brasília, DF, 6 maio 1999. Disponível em: https://www.planalto.gov.br/ccivil_03/decreto/D3048.htm. Acesso em: 8 maio 2018.

BRASIL. Ministério da saúde. Manual de exposição ocupacional: recomendações para atendimento e acompanhamento de exposição ocupacional a material biológico: HIV e hepatites B e C. Brasília, DF: Ministério da Saúde, $2004 . \quad$ Disponível: http://bvsms.saude.gov.br/bvs/publicacoes/04manual_acidentes.pdf. Acesso em: 23 abr. 2019.

BRASIL. Ministério do Trabalho e Emprego. Portaria $n^{\circ} 485$, de 11 de novembro de 2005. Norma Regulamentadora 32: Segurança e saúde no trabalho em estabelecimentos de saúde. Diário Oficial da União, Brasília, DF, 16 nov. 2005. Disponível em: <http://www.mte.gov.br/legislacao/normas_regulamentadoras/nr_32.pdf>. Acesso em: 12 set. 2017.

BRASIL. Ministério da Saúde. Portaria $n^{\circ}$ 104, de 25 de janeiro de 2011. Define as terminologias adotadas em legislação nacional, conforme o disposto no Regulamento Sanitário Internacional 2005 (RSI 2005), a relação de doenças, agravos e eventos em saúde pública de notificação compulsória em todo o território nacional e estabelece fluxo, critérios, responsabilidades e atribuições aos profissionais e serviços de saúde. Diário Oficial da União, Brasília, DF, 26 jan. 2011. Disponível em: http://bvsms.saude.gov.br/bvs/saudelegis/gm/2011/prt0104_25_01_2011.html. Acesso em: 23 abr. 2019.

BRASIL. Ministério da Saúde. Portaria n 1.271, de 6 de junho de 2014. Define a Lista Nacional de Notificação Compulsória de doenças, agravos e eventos de saúde pública nos serviços de saúde públicos e privados em todo o território nacional, nos termos do anexo, e dá outras providências. Diário Oficial da União, Brasília, DF, 9 jun. 2014. Disponível em: http://bvsms.saude.gov.br/bvs/saudelegis/gm/2014/prt1271_06_06_2014.html. Acesso em: 23 abr. 2019.

BRASIL. Ministério da Saúde. Portaria n 204, de 17 de fevereiro de 2016. Define a Lista Nacional de Notificação Compulsória de doenças, agravos e eventos de saúde pública nos serviços de saúde públicos e privados em todo o território nacional, nos termos do anexo, e dá outras providências. Diário Oficial da União, Brasília, DF, 18 fev. 2016a. Disponível em: http://bvsms.saude.gov.br/bvs/saudelegis/gm/2016/prt0204_17_02_2016.html. Acesso em: 23 abr. 2019.

BRASIL. Ministério da Saúde. Portaria $n^{\circ} 205$, de 17 de fevereiro de 2016. Define a lista nacional de doenças e agravos, na forma do anexo, a serem monitorados por meio da estratégia de vigilância em unidades sentinelas e suas diretrizes. Diário Oficial da União, Brasília, DF, 18 fev. 2016b. Disponível em: http://bvsms.saude.gov.br/bvs/saudelegis/gm/2016/prt0205_17_02_2016.html. Acesso em: 23 abr. 2019.

. Lei $n^{\circ}$ 13.429, de 31 de março de 2017. Altera dispositivos da Lei $n^{\circ} 6.019$, de 3 de janeiro de BRASIL 1974, que dispõe sobre o trabalho temporário nas empresas urbanas e dá outras providências; e dispõe sobre as relações de trabalho na empresa de prestação de serviços a terceiros. Diário Oficial da União, Brasília, DF, 31 mar. 2017. Disponível em: http://www.planalto.gov.br/ccivil_03/_Ato2015-2018/2017/Lei/L13429.htm. Acesso em: 23 abr. 2019.

CARVALHO, P. F. et al. Exposição a material biológico envolvendo trabalhadores em hospital especializado em doenças infecciosas. Revista Baiana de Enfermagem, Salvador, v. 30, n. 3, p. 1-9, jul./set. 2016. DOI: http://dx.doi.org/10.18471/rbe.v30i3.15670. Disponível em: <https://portalseer.ufba.br/index.php/enfermagem/article/view/15670>. Acesso em: 16 de ago de 2018. https://doi.org/10.18471/rbe.v30i3.15670

CDC. Workbook for designing, implementing and evaluating a Sharps Injury Prevention Program. Washington: Centers for Disease Control and Prevention, 2008. Disponível em: https://www.cdc.gov/sharpssafety/pdf/sharpsworkbook_2008.pdf. Acesso em: 23 abr. 2019. 
FUKUDA, H.; YAMANAKA, N. Reducing needlestick injuries through safety-engineered devices: results of a Japanese multi-centre study. Journal of Hospital Infection, [internet], v. 02, p. 147-153, feb. $\quad 2016 . \quad$ DOI: https://doi.org/10.1016/j.jhin.2015.09.019. Available en:<https://www.sciencedirect.com/science/article/pii/S0195670115003953>. Access: 27 feb. 2019. https://doi.org/10.1016/j.jhin.2015.09.019

IBGE. Uberaba. IBGE Cidades, 2018. Disponível em: https://cidades.ibge.gov.br/brasil/mg/uberaba/panorama. Acesso em: 13 abr. 2019.

MACHADO, M. H. et al. Características gerais da enfermagem: o perfil sócio demográfico. Enfermagem em Foco, online, v. 7, p. 9-14, 2016. DOI: 10.21675/2357-707X.2016.v7.nESP.68 Disponível em: <http://biblioteca.cofen.gov.br/wp-content/uploads/2016/07/Caracter\%C3\%ADsticasgerais-da-enfermagem-o-perfil-s\%C3\%B3cio-demogr\%C3\%A1fico.pdf>. Acesso em: Acesso em: 04 nov. 2019.

MACHADO, M. P. M. S. et al. Imunidade para hepatite B entre trabalhadores de um hospital de referência em doenças infectocontagiosas, vítimas de acidente com material biológico. Revista de Saúde e Ciências Biológicas, Fortaleza, v. $5, \quad$ n. 1, p. 62-70, 2017. DOI: http://dx.doi.org/10.12662/2317-3076jhbs.v5i1.1018.p62-70.2017. Disponível em: <https://periodicos.unichristus.edu.br/jhbs/article/view/1018>. Acesso em: 05 set. 2019. https://doi.org/10.12662/2317-3076jhbs.v5i1.1018.p62-70.2017

MACHI JUNIOR, A. et al. Outcomes of accidents at work with exposure to biological agentes. Journal of Human Growth and Development, São Paulo, v. 24, n. 3, p. 249-254, 2014. Available en: $<$ http://pepsic.bvsalud.org/scielo.php?script=sci arttext\&pid=S0104$12822014000300003 \&$ lng=pt\&nrm=iso\&tlng=pt>. Access: 05 jan. 2019.

MIRANDA, F. M. A. et al. Perfil dos trabalhadores brasileiros vítimas de acidente de trabalho com fluidos biológicos. Revista Brasileira de Enfermagem, Brasília, v. 70, n. 5, p. 1117-1124, set./out. 2017. DOI: http://dx.doi.org/10.1590/0034-7167-2016-0482. Disponível em: <https://www.redalyc.org/articulo.oa?id=267052669024>. Acesso em: 11 fev. 2019.

PHILLIPS, E. K.; CONAWAY, M. R.; JAGGER, J. C. Percutaneous injuries before and after the Needlestick Safety and Prevention Act. The New England Journal of Medicine, v. 366, n. 7, p. 670671, fev. 2012. Disponível em: http://www.nejm.org/doi/pdf/10.1056/NEJMc1110979. Acesso em: 23 abr. 2019. https://doi.org/10.1056/NEJMc1110979

SANTOS JUNIOR, E. P. et al. Acidente de trabalho com material perfurocortante envolvendo profissionais e estudantes da área da saúde em hospital de referência. Revista Brasileira de Medicina do Trabalho, São Paulo, v. 13, n. 2, p. 69-75, 2015. Disponível em: $<$ http://www.rbmt.org.br/details/6/pt-BR/acidente-de-trabalho-com-material-perfurocortante-

envolvendo-profissionais-e-estudantes-da-area-da-saude-em-hospital-de-referencia>. Acesso em: 23 de out. 2019.

SOARES, W. K. R.et al. Incidence of accidents with perforocortants in health professionals in a hospital of great port in the Legal Amazon. Brazilian Journal of Health Review, Curitiba, v. 1, n. 1, p. 51-69, 2018. Available en: <http://www.brjd.com.br/index.php/BJHR/article/view/559>. Access: 25 aug. 2019. 